\title{
Effects of Cerebellar tDCS on Inhibitory Control: Evidence from a Go/NoGo Task
}

\author{
Daniela Mannarelli ${ }^{1}$ - Caterina Pauletti ${ }^{1}$ - Alessia Petritis ${ }^{1} \cdot$ Roberto Delle Chiaie $^{1} \cdot$ Antonio Currà $^{2}$. \\ Carlo Trompetto $^{3,4}$ - Francesco Fattapposta ${ }^{1}$
}

Published online: 14 July 2020

(C) The Author(s) 2020

\begin{abstract}
Response inhibition as an executive function refers to the ability to suppress inappropriate but prepotent responses. Several brain regions have been implicated in the process underlying inhibitory control, including the cerebellum. The aim of the present study was to explore the role of the cerebellum in executive functioning, particularly in response inhibition. For this purpose, we transitorily inhibited cerebellar activity by means of cathodal tDCS and studied the effects of this inhibition on ERP components elicited during a Go/NoGo task in healthy subjects. Sixteen healthy subjects underwent a Go/NoGo task prior to and after cathodal and sham cerebellar tDCS in separate sessions. A reduction in N2-NoGo amplitude and a prolongation in N2-NoGo latency emerged after cathodal tDCS whereas no differences were detected after sham stimulation. Moreover, commission errors in NoGo trials were significantly higher after cathodal tDCS than at the basal evaluation. No differences emerged between performances in Go trials and those after sham stimulation. These data indicate that cerebellar inhibition following cathodal stimulation alters the ability to allocate attentional resources to stimuli containing conflict information and the inhibitory control. The cerebellum may regulate the attentional mechanisms of stimulus orientation and inhibitory control both directly, by making predictions of errors or behaviors related to errors, and indirectly, by controlling the functioning of the cerebral cortical areas involved in the perception of conflict signals and of the basal ganglia involved in the inhibitory control of movement.
\end{abstract}

Keywords Cerebellum $\cdot$ Healthy subjects $\cdot$ Cognition $\cdot$ Go/NoGo $\cdot$ tDCS

\section{Introduction}

Response inhibition refers to the ability to suppress inappropriate but prepotent responses [1, 2]. Several brain regions, including the ventrolateral and dorsolateral prefrontal cortices, the supplementary motor area (SMA) [3-6], the inferior frontal gyrus (IFG), and the anterior cingulate cortex (ACC), have been implicated in the process underlying response inhibition [7-9].

Previous studies have pointed to a possible role of the cerebellum in executive functioning, specifically in response
Daniela Mannarelli

daniela.mannarelli@uniroma1.it

Caterina Pauletti

caterina.pauletti@uniroma1.it

Alessia Petritis

alessiapetritis@gmail.com

Roberto Delle Chiaie

r.dellechiaie@centrokahlbaum.it

Antonio Currà

antonio.curra@uniromal.it

Carlo Trompetto

ctrompetto@neurologia.unige.it
Francesco Fattapposta

francesco.fattapposta@uniroma1.it

1 Department of Human Neuroscience, Sapienza University of Rome, Viale dell'Università 30, Rome, Italy

2 Department of Medical-Surgical Sciences and Biotechnologies, A. Fiorini Hospital, Terracina, LT, Sapienza University of Rome, Polo Pontino, Latina, Italy

3 Department of Neuroscience, Rehabilitation, Ophthalmology, Genetics, Maternal and Child Health, University of Genova, Genoa, Italy

4 Department of Neuroscience, IRCCS Ospedale Policlinico San Martino, Genoa, Italy 
inhibition. Indeed, cerebellar activation has been documented both by functional neuroimaging studies in healthy subjects during selective cognitive tasks designed to explore inhibitory control, such as the Stroop Color Word Test or the "Tower of London" test [10-12], and by clinical studies on patients with cerebellar lesions [13-15]. However, cerebellar activation during cognitive tasks does not necessarily indicate cognitive processing but may instead reflect subtle contaminations by task-related motor demands. Moreover, lesions in the cerebellum often do not occur in isolation, making conclusions about the specific effects of cerebellar lesions difficult. The cerebellar role in response inhibition consequently has yet to be fully understood [16].

In a recent study by our group, cerebellar inhibition induced by means of cathodal transcranial direct current stimulation (tDCS) in healthy subjects revealed the presence of an executive attentive dysfunction during the attention network test (ANT) that was specifically related to the ability to promote an adequate discrimination of stimuli containing conflict or error information [17].

Response inhibition may be studied by means of the event-related potential (ERP) technique and examining the brain electrophysiological responses during a Go/NoGo task. Typically, in a Go/NoGo task, participants rapidly respond to Go stimuli while withholding responses to NoGo stimuli. Many studies have suggested that processing of the Go stimulus, which is generally related to a motor response, is associated with the elicitation of two specific psychophysiological components: the $\mathrm{N} 2$ component (with maximal central peak) [18], which reflects the initial orienting to the stimulus [19], and the P3 component (with maximal parietal peak) [20-22], which is related to the attentive discrimination of the stimulus $[23,24]$. Similarly, the NoGo stimulus is associated with the appearance of the $\mathrm{N} 2$ component (with greater frontal amplitude) $[18,25]$ and P3 component (with greater central amplitude) $[20,21,26,27]$. In particular, the NoGo-N2 component is considered an earlier step of response inhibition that indicates the conflict between the internal representation of the Go response and the NoGo stimulus has been detected [27-29]. By contrast, the NoGo-P3 component may represent a later stage of response inhibition that reflects both the response evaluation and the cancelation of the planned response [30-33].

The aim of the present study was to more thoroughly explore the role of the cerebellum in executive functioning, particularly in response inhibition. For this purpose, we transitorily inhibited cerebellar activity by means of cathodal tDCS and studied the effects on ERP components elicited during a Go/NoGo task in healthy subjects.

Non-invasive brain stimulation techniques, such as tDCS, can be used to gain valuable insights into the neural mechanisms underlying cognitive processing. TDCS allows polarity-dependent stimulation, which results in differential cortical excitability changes [34]. These so-called after-effects are believed to be mediated by changes in membrane polarization thresholds via glutamatergic synapses and intracortical interneurons [35]. Although the after-effects of tDCS may differ between subjects depending on the tDCS intensity applied, the duration, the timing [36, 37], and the cognitive status of the subjects [38-42], cathodal tDCS is believed to reduce neuronal excitability and anodal tDCS to increase it [34, 43].

As regards cerebellar tDCS, several studies have demonstrated that anodal stimulation does not induce cognitive effects if applied to healthy subjects. Indeed, it has been reported that functions already adequately expressed in basic conditions cannot be enhanced further [44, 45]. Cathodal cerebellar stimulation can instead affect the execution of cognitive tasks, particularly by altering the processing of the acoustic stimulus, and result in a dysfunction of the attentive executive network [17, 44, 45]. As suggested by the results of these studies, the presence of cerebellar inhibition after cathodal tDCS may induce hyperactivity in brain areas $[17,45]$ following a reduction in the physiological cerebellar-brain inhibition tone (CBI) [46] in multiple brain areas. The hyperactivity in these cortical regions may, however, also be associated with uncoordinated functioning as well as with possible cognitive dysfunctions [17].

From an anatomo-functional point of view, the right cerebellar hemisphere is believed to play a prominent role in executive functions $[49,50]$ in view of the cerebro-cerebellar cross-connections and the important role played by the left frontal-parietal areas in the control of executive processes $[47,48]$. It is for this reason that the right cerebellar hemisphere was chosen as a target for the application of tDCS in the present study.

On the basis of these assumptions, we hypothesized that cathodal tDCS over the right cerebellum reduces the amplitude of the N2 and P3 components elicited during a Go/NoGo task, particularly following the NoGo stimulus.

\section{Methods}

\section{Subjects}

Sixteen right-handed, healthy subjects ( 8 male, 8 female; mean age $25.7 \pm 3.5$ years; range $22-35$ years) were enrolled in a double-blind, sham-controlled, crossover study. None of the subjects had a history of neurological or psychiatric disease or of head injury, and none reported consuming excessive amounts of alcohol or were taking any medication that affects the central nervous system. Written informed consent was obtained from all the subjects prior to the experiment. The study was approved by the Local Medical Ethics Committee. 


\section{Procedure}

Each subject received cathodal or sham tDCS stimulation during two randomized tDCS sessions performed at least 6 days apart. Both before and after tDCS stimulation, subjects reported their attention, fatigue, and perceived pain using a selfscored visual analogue scale [51] and underwent a psychophysiological evaluation.

\section{tDCS}

None of the subjects or ERP investigators, with the exception of the investigator who applied the tDCS, was aware of whether cathodal or sham stimulation was being performed. The experimenter was present in the room at the beginning of each session so as to be able to start the tDCS system; she was not in the room during the stimulation phase, though subjects could call her and interrupt the tDCS procedure if any problem arose. During tDCS session, subjects were not engaged in any specific motor or cognitive task.

TDCS over the right cerebellar hemisphere was applied by means of two sponge electrodes (surface area $=25 \mathrm{~cm}^{2}$ ) moistened with a saline solution. One electrode was centered over the right cerebellar cortex, $1 \mathrm{~cm}$ below and $4 \mathrm{~cm}$ lateral to the inion (corresponding approximately to the projection of cerebellar lobule VII onto the scalp). The other electrode was positioned over the right deltoid muscle [52]. The onset and offset of all the interventions (cathodal and sham) entailed increasing and decreasing the current, respectively, in a ramp-like manner over $10 \mathrm{~s}$, a method shown to achieve a good level of blinding between sessions [45, 53, 54]. The stimulation intensity was set at $2 \mathrm{~mA}$ and delivered over the cerebellum for 20 min using a battery-operated, constant current stimulator (BrainSTIM EMS Srl, Bologna, Italy), which is similar to the intensity adopted by Ferrucci et al. (2008) [52] and is considered to be well below the tissue damage threshold $[53,55,56]$. In the sham condition, pseudo-stimulation (110 uA over $15 \mathrm{~ms}$ every $550 \mathrm{~ms}$ ) instead of the stimulation current was applied for $20 \mathrm{~min}$ [45].

\section{Psychophysiological Evaluation}

The psychophysiological evaluation consisted of a Go/NoGo task and a simple reaction time task separated by a short interval. The two tasks were delivered in a randomized order between subjects and between sessions within subjects.

\section{Go/NoGo Task}

Two consecutive blocks of an unwarned equiprobable auditory Go/NoGo task were presented via circumaural headphones. Each block consisted of 150 tones (intensity, $60 \mathrm{~dB}$ SPL; duration, $50 \mathrm{~ms}$; rise/fall time, $5 \mathrm{~ms}$ ) presented with a fixed stimulus onset asynchrony (SOA) of $1100 \mathrm{~ms}$ and a fixed inter-stimulus interval (ISI) of $1040 \mathrm{~ms}$. Half the tones were $1000 \mathrm{~Hz}$ and the other half were $1500 \mathrm{~Hz}$; the tones were delivered in a randomized order. Subjects were required to button-press with their dominant hand in response to one of the tones (named Go stimulus), while they had to ignore the other (named NoGo stimulus); the Go tone frequency alternated between the blocks, and the frequency of the first block Go tone was counterbalanced between participants to avoid any consistent sequence effects between subjects. The task lasted about $10 \mathrm{~min}$.

\section{Simple Reaction Time Task}

A simple reaction time task was performed as a control measure. The task consisted of two consecutive blocks of 75 acoustic tones (intensity, $60 \mathrm{~dB}$ SPL; duration, $50 \mathrm{~ms}$; rise/ fall time, $5 \mathrm{~ms}$ ) with a fixed SOA of $1100 \mathrm{~ms}$. Tones of 1000 or $1500 \mathrm{~Hz}$ were presented; only one type of stimulus was presented in each block. The order of the blocks was counterbalanced between participants. The subjects were instructed to push a button upon presentation of each stimulus (named Go stimulus). The task lasted about $5 \mathrm{~min}$.

\section{EEG Recording}

Subjects were seated in an anatomic chair in a faradized and light-attenuated room. The electrophysiological signals were recorded by means of a 21-channel cap with active electrodes at the $\mathrm{F} 3, \mathrm{Fz}, \mathrm{F} 4, \mathrm{C} 3, \mathrm{Cz}, \mathrm{C} 4, \mathrm{P} 3, \mathrm{Pz}$, and $\mathrm{P} 4$ sites, according to the International 10-20 System, referred to linked mastoids and grounded at the forehead. The vertical electro-oculogram (VEOG) was recorded from above and below the left eye; a horizontal EOG (HEOG) was also performed using electrodes placed at the two external canthi. All inter-electrode impedances were kept below $3 \mathrm{kOhm}$. EEG signals and EOG were filtered using a $0.01-30 \mathrm{~Hz}$. The data were digitized with an analogue/digital converter at a sampling rate of $1024 \mathrm{~Hz}$ and stored on a hard disk. A Mizar Sirius EEG-EP multifunctional system was used.

\section{ERPs Analysis}

EEG data were clipped offline into epochs of $800 \mathrm{~ms}$ with a baseline correction of $100 \mathrm{~ms}$ before each stimulus. A first automatic procedure was used to reject trials containing drift deflection exceeding $\pm 100 \mu \mathrm{V}$ in any channel including EOG, according to clinical guidelines [57]. A further offline analysis was performed to exclude ocular artifacts (eye movements/ blinks), according to a standard algorithm [58] implemented in our analyzer software (ERPLAB Toolbox). Trials containing artifacts were eliminated by computing the cross-covariance between the single-trial EOG waveform and a 200-ms step function and rejecting trials on which the maximum covariance 
exceeded a $\pm 15 \mu \mathrm{V}$ threshold. Lastly, the detection of artifacts was verified by visual inspection. Artifact rejection accounted for $5.9 \pm 0.6 / 150$ (3.9\%) of the trials for the Go/NoGo task and $3.7 \pm 1.7 / 75$ (4.9\%) for the simple RT task.

For each subject, all the artifact-free trials were averaged per stimulus (Go, NoGo) and filtered with a low-pass digital filter of $20 \mathrm{~Hz}$. The mean number of trials included was 138.1 $\pm 3.5 / 150$ (92.1\%) for the Go/NoGo task (cathodal: $138.7 \pm$ $3.5 / 150(92.5 \%)$ total; $138.1 \pm 3.7$ for the pre-tDCS session (Go, 69.4 \pm 1.7 ; NoGo, 68.8 \pm 2.5 ), $139.3 \pm 3.3$ for the posttDCS session (Go, 69.5 \pm 2.3 ; NoGo, $69.8 \pm 1.7$ ); sham: $137.4 \pm 3.5 / 150(91.6 \%)$ total; $137.3 \pm 3.8$ for the pre-tDCS session (Go, $69 \pm 2.6$; NoGo, 68.3 \pm 2.2 ), $137.6 \pm 3.3$ for the post-tDCS session (Go, 69.4 \pm 2.3 ; NoGo, 68.2 \pm 2.2$)$ ). For the simple RT task, the mean number of trials included was $71.3 \pm 1.6 / 75$ (95.1\%) (cathodal: $71.3 \pm 1.4 / 75(95.1 \%)$ total; $71.6 \pm 1.0$ for pre-tDCS session, $71.2 \pm 1.7$ for post-tDCS session; sham: $71.3 \pm 1.7 / 75$ (95.1\%) total; $71.1 \pm 1.7$ for pretDCS session, $71.4 \pm 1.8$ for post-tDCS session).

Scalp electrode activity was measured at all the electrode sites in which $\mathrm{Fz}, \mathrm{Cz}$, and $\mathrm{Pz}$ were analyzed. $\mathrm{Fz}, \mathrm{Cz}$, and $\mathrm{Pz}$ were chosen for the analyses because ERP responses are largest on the midline locations. As regards the Go/NoGo task, the $\mathrm{N} 2$ amplitude was measured as the mean voltage between 180 and $240 \mathrm{~ms}$ after Go and NoGo stimuli, while the N2 latency was calculated as the midpoint latency, i.e., the time point that divided the area under the curve into two equal halves. The P3 amplitudes were calculated as the mean voltage between 250 and $500 \mathrm{~ms}$ in the Go and NoGo responses, respectively. The P3 latencies were also calculated for each stimulus as the midpoint latency of the same temporal window.

As regards the simple reaction time task, the $\mathrm{P} 3$ amplitude, defined as the mean voltage between 250 and $500 \mathrm{~ms}$, and the P3 latencies, defined as the midpoint latency of the same temporal window, were calculated as grand average of the Go stimuli in the two blocks.

Performance measures were also obtained by calculating the mean reaction times (RTs) of correct responses (correct responses ranged between 180 and $1000 \mathrm{~ms}$ ) and the accuracy of the responses expressed as the absolute number of errors (commission errors to NoGo trials, omission responses to Go trials or Go RT $<180>1000 \mathrm{~ms}$ for Go/NoGo task; omission responses or RT $<180>1000 \mathrm{~ms}$ for the simple reaction time task) for both the simple reaction time task and the Go/NoGo task.

\section{Statistical Analysis}

Data are expressed as the mean ( \pm 1 standard deviation) for continuous variables and as proportions for categorical variables. The Shapiro-Wilk test was applied to assess the normal distribution of the data. All the psychophysiological data were normally distributed so that a parametric statistics was applied, with the exception of errors that were not normally distributed and required a non-parametric statistics.

For the Go/NoGo task, the ERP parameters (N2 and P3 amplitudes and latencies) were analyzed separately by means of ANOVA for repeated measures (rmANOVA), with the "stimulus" (Go-NoGo), the experimental "condition" (cathodal, sham), the "electrode" (Fz, Cz, Pz), and the "timing" (pretDCS and post-tDCS) as the within-subject factors. When necessary, a post hoc correction according to Bonferroni was then applied. Degrees of freedom were adjusted, when necessary, by using the Greenhouse-Geisser epsilon coefficient for possible violations of the sphericity assumption. Corrected $p$ values are reported; the original degrees of freedom are reported together with their correction factor epsilon. Effect sizes were measured by calculating the partial eta squared $\left(\eta_{\mathrm{p}}^{2}\right)$. We interpreted the magnitude of the effect size provided by $\eta_{\mathrm{p}}^{2}$ according to the following guidelines: $=0.01$ small effect; $=0.06$ medium effect; $=0.14$ large effect [59].

Similarly, for the SRT task, ERP parameters (P3 amplitudes and latencies) were analyzed separately by means of rmANOVA, with the experimental "condition" (cathodal, sham), the "electrode" (Fz, Cz, Pz), and the "timing" (pre-tDCS and post-tDCS) as the within-subject factors. When necessary, a post hoc correction according to Bonferroni was then applied.

Incorrect responses (omission errors to Go trials in the $\mathrm{Go} /$ NoGo task and to SRT trials, and commission errors to NoGo trials or false alarms (FA)) were analyzed separately for each condition and timing (pre-cathodal, post-cathodal, pre-sham, post-sham) by means of Friedman test followed, when necessary, by the Wilcoxon signed-rank post hoc test with Bonferroni's correction.

Finally, reaction times (RT) in the Go trials in the Go/ NoGo task and those in the SRT trials were analyzed separately by means of rmANOVA, with the experimental "condition" (cathodal, sham) and the "timing" (pre-tDCS and posttDCS) as the within-subject factors.

Attention, fatigue, and perceived pain pre-tDCS and posttDCS were analyzed separately for each condition (cathodal, anodal, sham) by means of the Wilcoxon signed-rank test. A post hoc correction according to Bonferroni was applied if necessary.

The significance level was set at $p \leq 0.05$. The analyses were performed using the SPSS statistical package (Version 25).

\section{Results}

All subjects completed the two tDCS sessions without any complications. The subjects' self-reported ratings of attention, fatigue, and perceived pain were not significantly different prior to and after tDCS stimulation across the two sessions (Table 1). For each session, the psychophysiological tasks were completed within $30 \mathrm{~min}$ of the cessation of tDCS. 
Table 1 Psychological measures at pre-tDCS and post-tDCS evaluation

\begin{tabular}{|c|c|c|c|c|c|c|c|c|c|}
\hline & \multicolumn{3}{|l|}{ Attention } & \multicolumn{3}{|l|}{ Fatigue } & \multicolumn{3}{|l|}{ Pain } \\
\hline & Pre-tDCS & Post-tDCS & $p$ & Pre-tDCS & Post-tDCS & $\mathrm{p}$ & Pre-tDCS & Post-tDCS & $p$ \\
\hline Cathodal & $8.7 \pm 1.4(8.75)$ & $8.7 \pm 1.4(9)$ & 0.89 & $9.2 \pm 0.9(9)$ & $9.0 \pm 0.8(9)$ & 0.46 & $9.6 \pm 0.7(10)$ & $9.6 \pm 0.7(10)$ & 1.00 \\
\hline Sham & $8.9 \pm 1.2(9.25)$ & $8.7 \pm 1.1(9)$ & 0.32 & $8.9 \pm 1.2(9)$ & $8.8 \pm 1.1(9)$ & 0.81 & $9.7 \pm 0.5(10)$ & $9.4 \pm 1.0(10)$ & 0.10 \\
\hline
\end{tabular}

Values are displayed as mean $\pm \mathrm{SD}$ (median) and depict the subject's choice in a visual analogue scale in which 1 represents poorest attention, maximal fatigue, and pain, and 10 represents maximal attention, least fatigue, and pain. Significance level was set at $p \leq 0.05$

Figure 1 shows the grand average of the ERP components obtained during the Go/NoGo task.

\section{Go/NoGo Task}

\section{N2}

\section{Amplitude}

RmANOVA revealed a main effect of the "stimulus" factor $\left(F_{1-15}=3.78 ; p=0.071 ; \eta_{\mathrm{p}}^{2}=0.20\right)$, with higher amplitudes
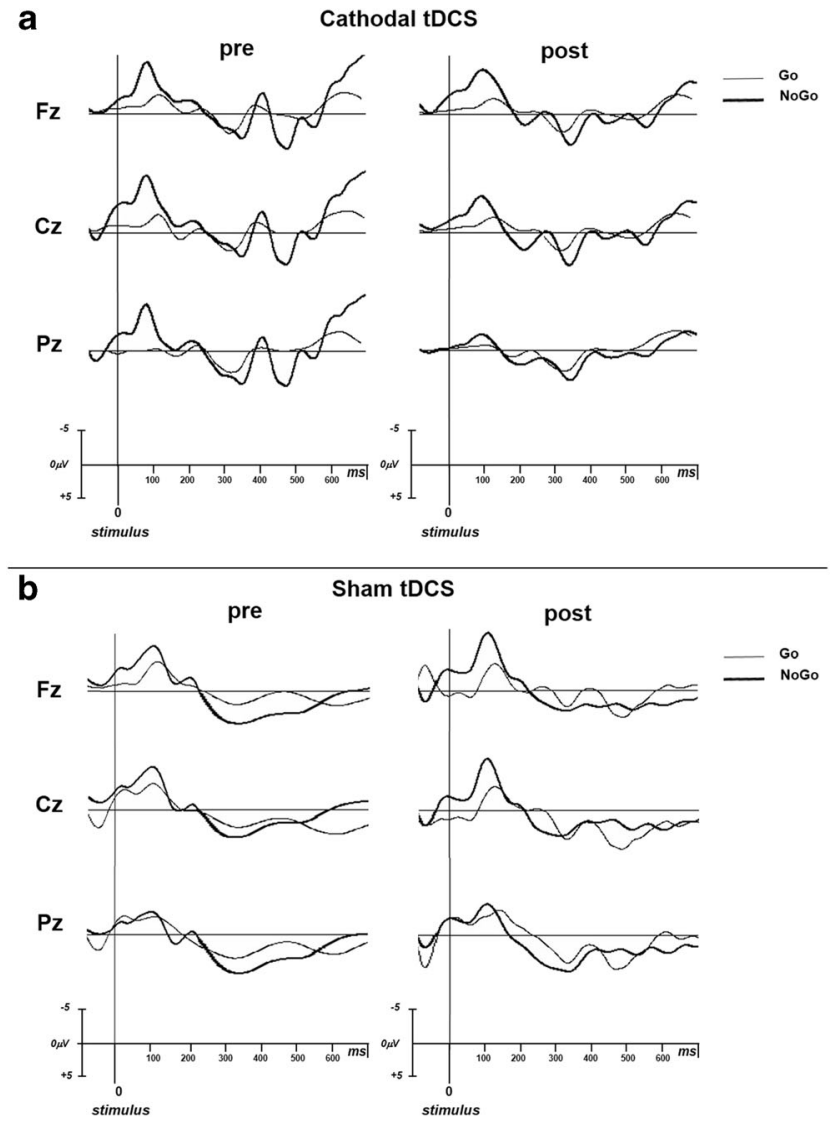

Fig. 1 ERP traces in mid-line scalp locations for Go (thin line) and NoGo stimulus (thick line), both in pre-tDCS and post-tDCS, for cathodal (a) and sham (b) condition. The analysis epoch was $800 \mathrm{~ms}$ with a $100 \mathrm{~ms}$ pre-stimulus baseline before the stimulus for the NoGo stimulus, of the "timing" factor $\left(F_{1-15}=6.06\right.$; $\left.p=0.026 ; \eta_{\mathrm{p}}^{2}=0.29\right)$, with higher amplitudes prior to stimulation, as well as of the "condition" factor $\left(F_{1-15}=4.55 ; p=\right.$ $0.050 ; \eta_{\mathrm{p}}^{2}=0.23$ ), with higher amplitudes for the sham stimulation. Moreover, a significant "condition" $\times$ "timing" $\times$ " stimulus" interaction emerged $\left(F_{1-15}=8.46, p=0.011, \eta_{\mathrm{p}}^{2}=\right.$ 0.36 ); after Bonferroni's correction, a significant difference emerged for the NoGo stimulus alone, with significantly lower amplitudes only after cathodal stimulation (pre, $-4.49 \mu \mathrm{V}$; post, $-1.19 \mu \mathrm{V} ; p<0.001)$. By contrast, no difference emerged for either the Go stimulus $(p=0.82)$ or after the sham condition (Go $p=0.85$; NoGo $p=0.91$ ). Significantly lower NoGo-N2 amplitudes were detected after cathodal stimulation in frontal, central, and parietal sites (Fz: $p=0.001 ; \mathrm{Cz}: p=$ 0.021; Pz: $p<0.001$ ) (Fig. 2a).

\section{Latency}

RmANOVA revealed a main effect of the "stimulus" factor alone $\left(F_{1-15}=25.37 ; p<0.001 ; \eta_{\mathrm{p}}^{2}=0.63\right)$, which yielded, as expected, shorter latency amplitudes for the NoGo stimulus; no significant effect emerged for the "timing" $\left(F_{1-15}=3.07 ; p=\right.$ $\left.0.10 ; \eta_{\mathrm{p}}^{2}=0.17\right)$, "condition" $\left(F_{1-15}=1.77 ; p=0.20 ; \eta_{\mathrm{p}}^{2}=\right.$ $0.10)$, or "electrode" $\left(F_{2-30}=0.07 ; p=0.93 ; \eta_{\mathrm{p}}^{2}=0.005\right)$ factors.

A significant "condition" $\times$ "timing" $\times$ "stimulus" interaction emerged $\left(F_{1-15}=5.23, p=0.037, \eta_{\mathrm{p}}^{2}=0.26\right)$. As observed for amplitude, after Bonferroni's correction, a significant difference was detected for the NoGo stimulus alone, with significantly longer latencies after cathodal stimulation (pre $=200.8 \mathrm{~ms} ;$ post $=232.6 \mathrm{~ms} ; p=0.003)$. By contrast, no difference was detected either for the Go stimulus $(p=0.93)$ or after the sham intervention (Go $p=0.94$; NoGo $p=0.59$ ). Significantly longer NoGo-N2 latencies after cathodal stimulation were detected in frontal, central, and parietal sites (Fz: $p=0.003 ;$ Cz: $p=0.003 ;$ Pz: $p=0.18$ ). (Fig. 2b).

\section{P3}

\section{Amplitude}

RmANOVA revealed a main effect of both the "stimulus" factor $\left(F_{1-15}=5.54 ; p=0.033 ; \eta_{\mathrm{p}}^{2}=0.27\right)$, with higher 
Fig. 2 Amplitudes (a) and latencies (b) of $\mathrm{N} 2$ components for Go and NoGo stimulus are presented separately for cathodal and sham condition, both in pretDCS and post-tDCS. Error bars indicate \pm 1 SE. $* p<0.05$

$$
\text { a }
$$

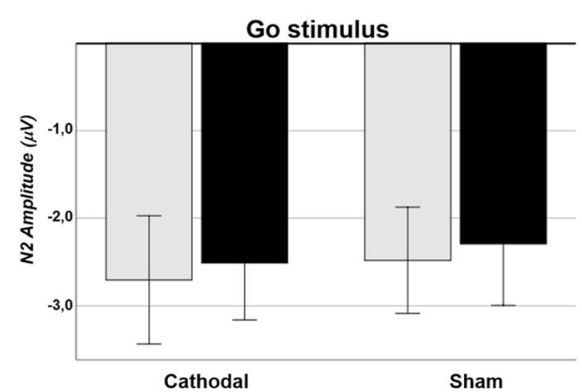

N2 Amplitude

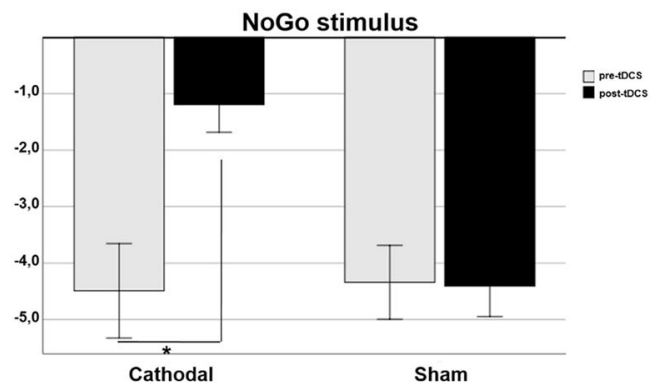

b

N2 Latency

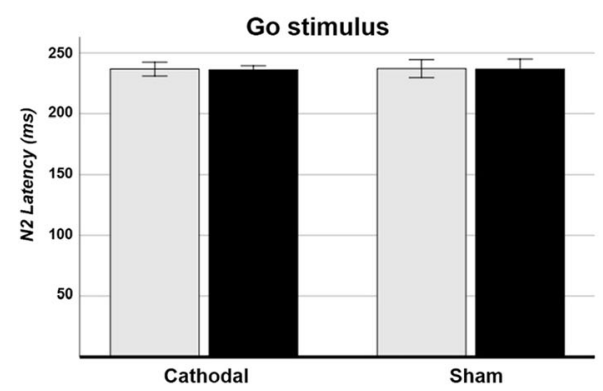

amplitudes for the NoGo stimulus, and the "electrode" factor $\left(F_{2-30}=19.1 ; p<0.001 ; \eta_{\mathrm{p}}^{2}=0.56\right)$, with higher amplitudes for centro-parietal than for frontal sites. No significant effect emerged for either the "timing" or the "condition" factors.

The "condition" $\times$ "timing" $\times$ "stimulus" interaction was not significant $\left(F_{1-15}=0.076, p=0.78, \eta_{\mathrm{p}}^{2}=0.005\right)$.

\section{Latency}

RmANOVA revealed a main effect of the "stimulus" factor alone $\left(F_{1-15}=3.60 ; p=0.077 ; \eta_{\mathrm{p}}^{2}=0.19\right)$, which yielded, as expected, longer latencies for the NoGo stimulus; no significant effect emerged for the "timing," "condition," or "electrode" factors.

The "condition" $\times$ "timing" $\times$ "stimulus" interaction was not significant $\left(F_{1-15}=0.044, p=0.83, \eta_{\mathrm{p}}^{2}=0.003\right)$.

\section{Performance Measures}

\section{Omissions (Go Stimulus)}

Friedman's test did not reveal a significant difference between omission errors measured pre- and post-tDCS stimulation $\left(\chi^{2}=0.12 ; p=0.99\right)$.

\section{False Alarms (NoGo Stimulus)}

Friedman's test showed a significant difference between false alarm errors measured pre- and post-tDCS stimulation $\left(\chi^{2}=\right.$ 34.72; $p<0.001)$; post hoc test using a Wilcoxon signed ranking test with Bonferroni-adjusted alpha level of 0.008 $(0.05 / 6)$ showed that only after cathodal stimulation, the number of FA significantly increased (pre $=0.37$; post $=3.25$; $z=$ $-3.6 ; p<0.001)$. No differences were detected in FA after sham stimulation (pre $=0.25$; post $=0.31 ; z=-0.14 ; p=$ 0.89) (see Fig. 3).

\section{Reaction Time}

ANOVA did not reveal a main effect of either the "condition" $\left(F_{1-15}=0.154 ; p=0.70 ; \eta_{\mathrm{p}}^{2}=0.010\right)$ or "timing" $\left(F_{1-15}=\right.$ $\left.0.034 ; p=0.857 ; \eta_{\mathrm{p}}^{2}=0.002\right)$ factors. Moreover, no significant "timing" $\times$ "condition" interaction was observed $\left(F_{1-15}=\right.$ $1.29 ; p=0.27 ; \eta_{\mathrm{p}}^{2}=0.08$ ).

\section{False Alarms}

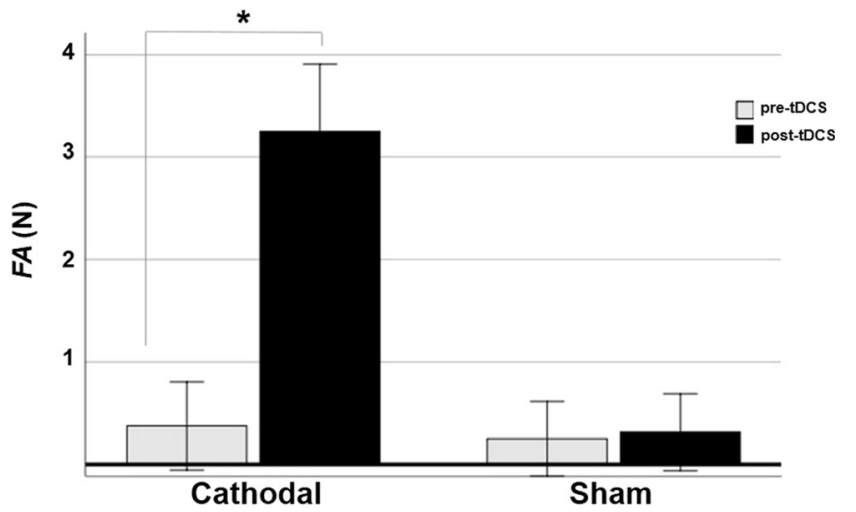

Fig. 3 False alarms are presented separately for cathodal and sham condition, both in pre-tDCS and post-tDCS. Error bars indicate \pm 1 SE. $* p<0.05$ 


\section{SRT Task}

\section{P3}

RmANOVA revealed a main effect of the "electrode" factor on P3 amplitude $\left(F_{2-30}=13.25, p<0.001, \eta_{\mathrm{p}}^{2}=0.47\right)$, which yielded, as expected, higher amplitudes in parietal sites than fronto-central sites. No other significant effect was observed (P3 amplitude: rest of Fs, $F<0.18$; rest of ps, $p>0.69$; P3 latency: all Fs, $F<0.497$; all ps, $p>0.6$ ).

\section{Performance Measures}

As regards reaction times, rmANOVA did not reveal a main effect of the "condition" $\left(F_{1-15}=0.124 ; p=0.73 ; \eta_{\mathrm{p}}^{2}=0.008\right)$ or "timing" $\left(F_{1-15}=1.49 ; p=0.24 ; \eta_{\mathrm{p}}^{2}=0.091\right)$ factors and no significant "timing" $\times$ "condition" interaction was ob$\operatorname{served}\left(F_{1-15}=0.449 ; p=0.51 ; \eta_{\mathrm{p}}^{2}=0.029\right)$.

As regards omission errors, Friedman's test did not reveal a significant difference between errors committed pre- and posttDCS stimulation $\left(\chi^{2}=0.48 ; p=0.92\right)$.

\section{Discussion}

The aim of the present study was to investigate the role of the cerebellum in executive attentional functioning, in particular in inhibitory control, by evaluating the effects of cerebellar tDCS on the ERP components evoked during a Go/NoGo task.

Our data suggest that the processing of the NoGo stimulus alone is affected by cerebellar inhibition. Indeed, after cathodal tDCS, the latency of the N2-NoGo component was selectively longer than that observed at the basal evaluation. These data indicate that the orienting and initial discrimination of the incongruous stimulus are delayed. Moreover, the significant decrease in N2-NoGo amplitude also points to a reduction in attentional resources after cerebellar inhibition. Cerebellar inhibition does not instead seem to affect closure of the cognitive processing of the NoGo stimulus, as is suggested by the stability of P3NoGo parameters before and after cathodal stimulation.

By contrast, processing of the Go stimulus does not appear to be affected by cerebellar inhibition in any of its phases, as indicated by the stability of both the N2 and P3 components before and after cathodal tDCS.

The Go stimulus is a stimulus that holds target information related to a motor act. Unlike the Go stimulus, the NoGo stimulus, which informs the subject to withhold the motor response, is by definition an incongruent stimulus and is thus able to activate on orienting response $[60,61]$. In this regard, the selective alterations observed in the N2-NoGo latency and amplitude suggest that cerebellar inhibition in this study determined a selective dysfunction in the shifting of attentional resources toward an incongruent stimulus, which in turn resulted in an inefficient orienting response.

The orienting response toward an incongruent stimulus usually involves frontal-parietal brain areas in the ventral attention network, which identifies salient changes in the environment and acts as an alert system or circuit-breaker for the dorsal attention system [62], the latter of which directs attention to the target stimuli related to a specific task. The brain areas believed to be involved most in the generation of an orienting response are the cingulate cortices, the lateral prefrontal cortex, and the inferior parietal cortex [63]. Indeed, combined EEG-fMRI studies have shown that the medium cingulate cortex and the anterior cingulate cortex are prevalently activated during tasks related to the processing of incongruent stimuli or errors [63-65]. Furthermore, the lateral prefrontal cortex has been implicated in the maintenance and updating of information and in top-down control, as well as in association with the ACC in the monitoring of stimuli containing conflict information [66-69].

The aforementioned areas present dense connections, through the thalamus, with subcortical structures, particularly with the basal ganglia and the cerebellum [70]. The cerebellum is believed to coordinate the functioning of activities in these brain areas by regulating the level of activation or inhibition and managing the timing, speed, and appropriateness of cognitive processes [46]. In particular, it has been demonstrated that cerebellar output is conveyed mainly by an inhibitory pathway (the cerebellar-brain inhibitory toneCBI) [46] that projects from the cerebellar cortex to the dentate nucleus and, from there, to the brain cortical areas through the thalamus $[17,71,72]$.

By inhibiting this physiological inhibitory control, cathodal stimulation may have resulted in these cortical areas becoming hyperactive and uncoordinated $[17,44]$. The non-synchronous and uncoordinated activation of areas involved in the perception of incongruous stimuli alters the orienting response specifically toward this kind of stimulus, which in turn elicits the psychophysiological components with a reduced amplitude. Indeed, the synchronized firing of cortical neurons activated by a selective cognitive task is known to be required to elicit psychophysiological components of an adequate amplitude [73-76].

This observation is in line with previous studies conducted by our group: a reduction in novelty-P3 amplitude was first observed after cerebellar cathodal stimulation [44]; moreover, an experiment in which ANT and tDCS were combined also highlighted the role of the cerebellum in executive attentional control specifically related to the processing of incongruous stimuli [17].

However, in a Go/NoGo task, the incongruous stimulus does not simply activate an orienting response. Within a Go/ NoGo paradigm, the subject, who is unaware of which stimulus will occur in the sequence, is constantly alerted by the 
stimulus arrival so as to allow a prompt motor response to the Go-stimulus. The NoGo stimulus inhibits the preparation and execution of this response. Thus, it is likely that the altered NoGo-N2 parameters reflect a difficulty in inhibitory motor control. This finding appears to be supported by the increased number of false alarms, which are by definition errors linked to a failure to inhibit the motor response after the NoGo stimulus. By contrast, the discrimination of the incongruent stimulus is performed adequately (as demonstrated by the preserved NoGo-P3 amplitude and latency).

The cerebellum is reported to be directly involved in the processing of incongruent stimuli and in the inhibitory control of movement since it is able to perform specific sensory predictions according to the anticipatory or feed-forward model $[77,78]$. Sensory predictions generated by a feed-forward model can be used to coordinate a motor act $[79,80]$, thereby providing a tool that plays a crucial role in anticipating the effects of a motor act and updating the motor system. These predictions may be compared with upcoming stimuli. If the predicted signals and the actual signals match, the afferent signals might not be considered whenever the system is updated. On the contrary, any difference that emerges between these stimuli constitutes a sensory prediction of the mismatch. As these signals of incongruity allow rapid adjustments in motor output, they may be considered indispensable to sensorimotor control. They are also crucial for learning, to refine future sensory predictions and to reduce the appearance of error on subsequent movements. The role of the cerebellum is likely to be related to the evaluation of temporal patterns of the stimulus as well as of those between stimuli and the related motor response [77]. Specifically, in a Go/NoGo task the cerebellum may help to generate a temporal contingency between the Go target stimulus and a motor response. When a NoGo stimulus appears, the role of the cerebellum is likely to exploit these conflict signals to improve future predictions and produce online changes in behavior related to incongruent information.

However, altered inhibitory control may even derive indirectly from a functional alteration of the basal ganglia. The basal ganglia include the subthalamic nucleus, which is connected both to the cerebellar cortex and to the deep cerebellar nuclei, and appears to act as the main gate for inhibitory control by regulating the functioning of supplementary motor areas [70, 81-83]. At the same time, the cerebellum seems to influence the functioning of the basal ganglia, and in particular of the indirect pathway, by modulating the activity of the striatal neurons connected with the external globus pallidus [84-86]. We believe that cathodal cerebellar inhibition alters inhibitory control by affecting the monitoring carried out by the basal ganglia of the programming, execution, and control of movements.

In summary, the executive attention dysfunction observed in our experiment, which is characterized by altered orienting to the incongruous stimulus associated with a reduction in inhibitory control, may derive in part from a direct cerebellar dysfunction and in part from an indirect dysfunction of the basal ganglia following cerebellar inhibition.

Our results do not seem to be in line with those of a previous study of Nozari et al. (2014) [87], which shows a facilitating effect for cognitive tasks after cathodal tDCS in the case in which the subjects were engaged in a minimally demanding task during stimulation. However, the authors used a different target of stimulation (prefrontal cortex instead of cerebellum) and a different cognitive task. In this perspective, these studies are not fully comparable.

To date, it is quite clear that the effects of tDCS can depend on several factors such as the applied tDCS intensity, duration, and timing stimulation [38-42] but also on task characteristics, the site of application, and the excitability status of the underlying cortical tissue [88]. This makes it rather difficult to find certain and repeatable effects of tDCS above all in cognitive studies [88, 89].

Given the relatively low focality of tDCS, we cannot rule out that neuronal activity in the right anterior cerebellum could be inhibited as well during cathodal session. In this sense, the higher false alarm rate following cathodal tDCS could be partly explain also with the inhibition of the motor response control. However, if the effect we found was purely motor, a variation of behavioral parameters would emerge also for the Go stimuli or during the simple reaction task. On the contrary, the reaction times to Go stimuli and the omission errors do not vary across sessions nor do the behavioral performances obtained during the simple reaction task. We believe that the effects induced by cerebellar cathodal inhibition are purely cognitive rather than related to motor-type effects.

To conclude, our experiment suggests that the cerebellum is involved in executive attentional functioning. In particular, the cerebellum seems to regulate attentional orienting to the stimulus and inhibitory control both directly, by making predictions of errors and behaviors related to errors, and indirectly, by controlling the functioning of the cerebral cortical areas involved in the perception of conflict signals and of the basal ganglia involved in the inhibitory control of movement.

Acknowledgements Open access funding provided by Università degli Studi di Roma La Sapienza within the CRUI-CARE Agreement.

\section{Compliance with Ethical Standards}

Written informed consent was obtained from all the subjects prior to the experiment. The study was approved by the Local Medical Ethics Committee.

Conflict of Interest The authors declare that they have no conflict of interest.

Open Access This article is licensed under a Creative Commons Attribution 4.0 International License, which permits use, sharing, adaptation, distribution and reproduction in any medium or format, as long as you give appropriate credit to the original author(s) and the source, 
provide a link to the Creative Commons licence, and indicate if changes were made. The images or other third party material in this article are included in the article's Creative Commons licence, unless indicated otherwise in a credit line to the material. If material is not included in the article's Creative Commons licence and your intended use is not permitted by statutory regulation or exceeds the permitted use, you will need to obtain permission directly from the copyright holder. To view a copy of this licence, visit http://creativecommons.org/licenses/by/4.0/.

\section{References}

1. Chambers CD, Garavan H, Bellgrove MA. Insights into the neural basis of response inhibition from cognitive and clinical neuroscience. Neurosci Biobehav Rev. 2009;33:631-46.

2. Bari A, Robbins TW. Inhibition and impulsivity: behavioral and neural basis of response control. Prog Neurobiol. 2013;108:44-79.

3. Garavan H, Ross TJ, Stein EA. Right hemispheric dominance of inhibitory control: an event-related functional MRI study. Proc Natl Acad Sci U S A. 1999;96:8301-6.

4. Chao HH, Luo X, Chang JL, Li CS. Activation of the presupplementary motor area but not inferior prefrontal cortex in association with short stop signal reaction time - an intra-subject analysis. BMC Neurosci. 2009;10:75.

5. Chen CY, Muggleton NG, Tzeng OJ, Hung DL, Juan CH. Control of prepotent responses by the superior medial frontal cortex. NeuroImage. 2009;44:537-45.

6. Swick D, Ashley V, Turken U. Are the neural correlates of stopping and not going identical? Quantitative meta-analysis of two response inhibition tasks. NeuroImage. 2011;56:1655-65.

7. Aron AR, Robbins TW, Poldrack RA. Inhibition and the right inferior frontal cortex: one decade on. Trends Cogn Sci. 2014;18: 177-85.

8. Botvinick MM, Cohen JD, Carter CS. Conflict monitoring and anterior cingulate cortex: an update. Trends Cogn Sci. 2004;8: 539-46.

9. Huster RJ, Enriquez-Geppert S, Lavallee CF, Falkenstein M, Herrmann CS. Electroencephalography of response inhibition tasks: functional networks and cognitive contributions. Int $\mathrm{J}$ Psychophysiol. 2013;87:217-33.

10. Lazeron RH, Rombouts SA, Machielsen WC, Scheltens P, Witter MP, Uylings HB, et al. Visualizing brain activation during planning: the tower of London test adapted for functional MR imaging. AJNR Am J Neuroradiol. 2000;21(8):1407-14.

11. Ravnkilde B, Videbech P, Rosenberg R, Gjedde A, Gade A. Putative tests of frontal lobe function: a PET-study of brain activation during Stroop's test and verbal fluency. J Clin Exp Neuropsychol. 2002;24:534-47.

12. Lie CH, Specht K, Marshall JC. Using fMRI to decompose the neural processes underlying the Wisconsin Card Sorting Test. NeuroImage. 2006;30:1038-49.

13. Schmahmann JD, Sherman JC. The cerebellar cognitive affective syndrome. Brain. 1998;121(4):561-79.

14. Botez-Marquard T, Bard C, Léveillé J, Botez MI. A severe frontalparietal lobe syndrome following cerebellar damage. Eur J Neurol. 2001;8(4):347-53.

15. Kalashnikova LA, Zueva YV, Pugacheva OV, Korsakova NK. Cognitive impairments in cerebellar infarcts. Neurosci Behav Psychol. 2005;35:773-9.

16. Sokolov AA, Miall RC, Ivry RB. The cerebellum: adaptive prediction for movement and cognition. Trends Cogn Sci. 2017;21(5): $313-32$.
17. Mannarelli D, Pauletti C, Currà A, Marinelli L, Corrado A, Delle Chiaie R, et al. The cerebellum modulates attention network functioning: evidence from a cerebellar transcranial direct current stimulation and attention network test study. Cerebellum. 2019;18(3): 457-68.

18. Nieuwenhuis S, Yeung N, Cohen JD. Stimulus modality, perceptual overlap and the go/no-go N2. Psychophysiology. 2004;41:15760 .

19. Piispala J, Kallio M, Bloigu R, Jansson-Verkasalo E. Delayed N2 response in Go condition in a visual Go/Nogo ERP study in children who stutter. J Fluen Disord. 2016;48:16-26.

20. Bokura H, Yamaguchi S, Kobayashi S. Electrophysiological correlates for response inhibition in a $\mathrm{Go} / \mathrm{NoGo}$ task. Clin Neurophysiol. 2001;112:2224-32.

21. Tekok-Kilic A, Shucard JL, Shucard DW. Stimulus modality and Go-NoGo effects on P3 during parallel visual and auditory continuous performance tasks. Psychophysiology. 2001;38:578-89.

22. Barry RJ, De Blasio FM. Sequential processing in the equiprobable auditory Go/NoGo task: a temporal PCA study. Int J Psychophysiol. 2013;89:123-7.

23. Verleger R, Ja'skowski P, Wascher E. Evidence for an integrative role of $\mathrm{P} 3 \mathrm{~b}$ in linking reaction to perception. J Psychophysiol. 2005;19:165-81.

24. Barry RJ, Rushby JA. An orienting reflex perspective on anteriorisation of the P3 of the event-related potential. Exp Brain Res. 2006;173:539-45.

25. Bekker EM, Kenemans JL, Verbaten MN. Source analysis of the N2 in a cued Go/NoGo task. Cogn Brain Res. 2005;22:221-31.

26. Johnstone SJ, Dimoska A, Smith JL, Barry RJ, Pleffer CB, Chiswick D, et al. The development of stop-signal and Go/Nogo response inhibition in children aged 7-12 years: performance and event-related potential indices. Int J Psychophysiol. 2007;63:2538.

27. Smith JL. To Go or not to Go, that is the question: do the N2 and P3 reflect stimulus- or response-related conflict? Int J Psychophysiol. 2011;82:143-52.

28. Falkenstein M, Hoormann J, Hohnsbein J. ERP components in Go/ Nogo tasks and their relation to inhibition. Acta Psychol. 1999;01: 267-91.

29. Randall WM, Smith JL. Conflict and inhibition in the cued-Go/ NoGo task. Clin Neurophysiol. 2011;122:2400-7.

30. Albert J, López-Martín S, Hinojosa JA, Carretié L. Spatiotemporal characterization of response inhibition. NeuroImage. 2013;76:27281 .

31. Donkers FCL, van Boxtel GJM. The N2 in go/no-go tasks reflects conflict monitoring not response inhibition. Brain Cogn. 2004;56: $165-76$.

32. Smith JL, Johnstone SJ, Barry RJ. Effects of pre-stimulus processing on subsequent events in a warned $\mathrm{Go} / \mathrm{NoGo}$ paradigm: response preparation, execution and inhibition. Int J Psychophysiol. 2006;61: 121-33.

33. Smith JL, Jamadar S, Provost AL, Michie PT. Motor and nonmotor inhibition in the Go/NoGo task: an ERP and fMRI study. Int J Psychophysiol. 2013;87:244-53.

34. Nitsche MA, Cohen LG, Wassermann EM, Priori A, Lang N, Antal A, et al. Transcranial direct current stimulation: state of the art 2008. Brain Stimul. 2008;1(3):206-23.

35. Stagg CJ, Nitsche MA. Physiological basis of transcranial direct current stimulation. Neuroscientist. 2011;17(1):37-53.

36. Jacobson L, Koslowsky M, Lavidor M. tDCS polarity effects in motor and cognitive domains: a meta-analytical review. Exp Brain Res. 2012;216:1-10.

37. Wiethoff S, Hamada M, Rothwell JC. Variability in response to transcranial direct current stimulation of the motor cortex. Brain Stimul. 2014;3:468-75. 
38. Teo F, Hoy KE, Daskalakis ZJ, Fitzgerald PB. Investigating the role of current strength in tDCS modulation of working memory performance in healthy controls. Front Psychiatry. 2011;2:45.

39. Ball K, Lane AR, Smith DT, Ellison A. Site-dependent effects of tDCS uncover dissociations in the communication network underlying the processing of visual search. Brain Stimul. 2013;6(6):95965.

40. Batsikadze G, Moliadze V, Paulus W, Kuo MF, Nitsche MA. Partially non-linear stimulation intensity-dependent effects of direct current stimulation on motor cortex excitability in humans. J Physiol. 2013;591(7):1987-2000.

41. Pirulli C, Fertonani A, Miniussi C. The role of timing in the induction of neuromodulation in perceptual learning by transcranial electric stimulation. Brain Stimul. 2013;6(4):683-9.

42. Pirulli $\mathrm{C}$, Fertonani A, Miniussi C. Is neural hyperpolarization by cathodal stimulation always detrimental at the behavioral level? Front Behav Neurosci. 2014;8:226.

43. Nitsche MA, Paulus W. Excitability changes induced in the human motor cortex by weak transcranial direct current stimulation. J Physiol. 2000;527(3):633-9.

44. Mannarelli D, Pauletti C, De Lucia MC, Delle Chiaie R, Bersani FS, Spagnoli F, et al. Effects of cerebellar transcranial direct current stimulation on attentional processing of the stimulus: evidence from an event-related potentials study. Neuropsychologia. 2016;84:12735.

45. Pope PA, Miall RC. Task-specific facilitation of cognition by cathodal transcranial direct current stimulation of the cerebellum. Brain Stimul. 2012;5:84-94.

46. Kelly RM, Strick PL. Cerebellar loops with motor cortex and prefrontal cortex of a nonhuman primate. J Neurosci. 2003;23(23): 8432-44.

47. Stroop JR. Studies of interference in serial verbal reactions. J Exp Psychol. 1935;18:643-62.

48. Le TH, Pardo JV, Hu X. 4T-fMRI study of nonspatial shifting of selective attention: cerebellar and parietal contributions. J Neurophysiol. 1998;79:1535-48.

49. Buckner RL, Krienen FM, Castellanos A, Diaz JC, Yeo BT. The organization of the human cerebellum estimated by intrinsic functional connectivity. J Neurophysiol. 2011;106(5):2322-45.

50. Buckner RL. The cerebellum and cognitive function: 25 years of insight from anatomy and neuroimaging. Neuron. 2013;80(3):80715 .

51. Stefan K, Cohen LG, Duque J, Mazzocchio R, Celnik P, Sawaki L, et al. Formation of a motor memory by action observation. $\mathrm{J}$ Neurosci. 2005;25:9339-46.

52. Ferrucci R, Marceglia S, Vergari M, Cogiamanian F, MrakicSposta S, Mameli F, et al. Cerebellar transcranial direct current stimulation impairs the practice dependent proficiency increase in working memory. J Cogn Neurosci. 2008;20:1687-97.

53. Nitsche MA, Liebetanz D, Lang N, Antal A, Tergau F, Paulus W. Safety criteria for transcranial direct current stimulation (tDCS) in humans. Clin Neurophysiol. 2003;114(11):2220-2.

54. Gandiga PC, Hummel FC, Cohen LG. Transcranial DC stimulation (tDCS): a tool for double-blind sham-controlled clinical studies in brain stimulation. Clin Neurophysiol. 2006;117:845-50.

55. Poreisz C, Boros K, Antal A, Paulus W. Safety aspects of transcranial direct current stimulation concerning healthy subjects and patients. Brain Res Bull. 2007;72(4-6):208-14.

56. Antal A, Alekseichuk I, Bikson M, Brockmöller J, Brunoni AR, Chen R, et al. Low intensity transcranial electric stimulation: safety, ethical, legal regulatory and application guidelines. ClinNeurophysiol. 2017;128(9):1774-809.

57. Duncan CC, Barry RJ, Connolly JF, Fischer C, Michie PT, Näätänen R, et al. Event-related potentials in clinical research: guidelines for eliciting, recording, and quantifying mismatch negativity, P300, and N400. Clin Neurophysiol. 2009;120:1883-908.
58. Woodman GF, Luck SJ. Serial deployment of attention during visual search. J Exp Psychol Hum Percept Perform. 2003;29:121-38.

59. Richardson JTE. Eta squared and partial eta squared as measures of effect size in educational research. Educ Res Rev. 2011;6:135-47.

60. Folstein JR, Van Petten C. Influence or cognitive control and mismatch of the N2 component of the ERP: a review. Psychophysiology. 2008;45:152-70.

61. Hoyniak C. Changes in the NoGo N2 event-related potential component across childhood: a systematic review and meta-analysis. Dev Neuropsychol. 2017;42(1):1-24.

62. Corbetta M, Patel G, Shulman GL. The reorienting system of the human brain: from environment to theory of mind. Neuron. 2008;58(3):306-24.

63. Posner MI, Petersen SE. The attention system of the human brain. Annu Rev Neurosci. 1990;13:25-42.

64. Posner MI, Raichle ME. Images of mind. New York: Scientific American library; 1994.

65. Posner MI, Walker JA, Friedrich FJ, et al. Effects of parietal lobe injury on covert orienting of visual attention. Neurosci. 1994;4: 1863-74.

66. Mostofski SH, Reiss AL, Lockhart P, Denckla MB. Evaluation of cerebellar size in attention-deficit hyperactivity disorder. J Child Neurol. 1998;13:434-9.

67. Van Zomeren AH, Brouwer WH. Clinical neuropsychology of attention. New York: Oxford university Press; 1994.

68. Fan J, McCandliss BD, Sommer T, Raz A, Posner MI. Testing the efficiency and independence of attentional networks. J Cogn Neurosci. 2002;14:340-7.

69. Posner MI. Orienting of attention. Q J Exp Psychol. 1980;41A:19 45.

70. Bostan AC, Dum RP, Strick PL. Cerebellar networks with the cerebral cortex and basal ganglia. Trends Cogn Sci. 2013;17(5):24154.

71. Ramnani N, Behrens TE, Johansen-Berg H, Richter MC, Pinsk MA, Andersson JL, et al. The evolution of prefrontal inputs to the cortico-pontine system: diffusion imaging evidence from macaque monkeys and humans. Cereb Cortex. 2006;16:811-8.

72. O'Reilly JX, Beckmann CF, Tomassini V, Ramnani N, JohansenBerg H. Distinct and overlapping functional zones in the cerebellum defined by resting state functional connectivity. Cereb Cortex. 2010;20:953-65.

73. Gray CM, König P, Engel AK, Singer W. Oscillatory responses in cat visual cortex exhibit inter-columnar synchronization which reflects global stimulus properties. Nature. 1989;338(6213):334-7.

74. Lopes da Silva F. Neural mechanisms underlying brain waves: from neural membranes to networks. Electroencephalogr Clin Neurophysiol. 1991;79(2):81-93.

75. Haarmann HI, Cameron KA, Ruchkin DS. Neural synchronization mediates on-line sentence processing: EEG coherence evidence from filler-gap constructions. Psychophysiology. 2002;39(6):8205.

76. Luck SJ, Woodman GF, Vogel EK. Event-related potential studies of attention. Trends Cogn Sci. 2000;4(11):432-40.

77. Baillieux H, DeSmet HJ, Paquier PF, DeDeyn PP, Mariën P. Cerebellar neurocognition: insights into the bottom of the brain. Clin Neurol Neurosurg. 2008;110(8):763-73.

78. Schmahmann JD. The role of the cerebellum in cognition and emotion: personal reflections since 1982 on the dysmetria of thought hypothesis, and its historical evolution from theory to therapy. Neuropsychol Rev. 2010;20(3):236-60.

79. Liu X, Robertson E, Miall RC. Neuronal activity related to the visual representation of arm movements in the lateral cerebellar cortex. J Neurophysiol. 2003;89:1223-37.

80. Ebner TJ, Hewitt AL, Popa LS. What features of limb movements are encoded in the discharge of cerebellar neurons? Cerebellum. 2011;10:683-93. 
81. Aron AR, Poldrack RA. Cortical and subcortical contributions to stop signal response inhibition: role of the subthalamic nucleus. J Neurosci. 2006;26(9):2424-33.

82. Bostan AC, Dum RP, Strick PL. The basal ganglia communicate with the cerebellum. Proc Natl Acad Sci U S A. 2010;107(18): $8452-6$.

83. Brunamonti E, Chiricozzi FR, Clausi S, Olivito G, Giusti MA, Molinari M, et al. Cerebellar damage impairs executive control and monitoring of movement generation. PLoS One. 2014;9(1): e85997.

84. Alexander GE, Crutcher MD. Functional architecture of basal ganglia circuits: neural substrates of parallel processing. Trends Neurosci. 1990;13(7):266-71.

85. Mink JW. The basal ganglia: focused selection and inhibition of competing motor programs. Prog Neurobiol. 1996;50(4):381-425.
86. Nambu A, Tokuno H, Takada M. Functional significance of the cortico-subthalamo-pallidal 'hyperdirect' pathway. Neurosci Res. 2002;43(2):111-7.

87. Nozari N, Woodard K, Thompson-Schill SL. Consequences of cathodal stimulation for behavior: when does it help and when does it hurt performance? PLoS One. 2014;9(1):e84338.

88. Miniussi C, Harris JA, Ruzzoli M. Modelling non-invasive brain stimulation in cognitive neuroscience. Neurosci Biobehav Rev. 2013;37(8):1702-12.

89. Oldrati V, Schutter DJLG. Targeting the human cerebellum with transcranial direct current stimulation to modulate behavior: a metaanalysis. Cerebellum. 2018;17(2):228-36.

Publisher's Note Springer Nature remains neutral with regard to jurisdictional claims in published maps and institutional affiliations. 